OPEN ACCESS

Edited by: Christian Wild

University of Bremen, Germany

Reviewed by:

Jian-Wen Qiu,

Hong Kong Baptist University, China

David Suggett,

University of Technology Sydney,

Australia

*Correspondence:

Sarah W. Davies

daviessw@gmail.com

${ }^{\dagger}$ These authors have contributed equally to this work.

Specialty section: This article was submitted to

Coral Reef Research,

a section of the journal

Frontiers in Marine Science

Received: 23 March 2016

Accepted: 15 June 2016

Published: 30 June 2016

Citation:

Davies SW, Marchetti A, Ries JB and Castillo KD (2016) Thermal and pCO Stress Elicit Divergent Transcriptomic Responses in a Resilient Coral.

Front. Mar. Sci. 3:112. doi: 10.3389/fmars.2016.00112

\section{Thermal and $p \mathrm{CO}_{2}$ Stress Elicit Divergent Transcriptomic Responses in a Resilient Coral}

\author{
Sarah W. Davies ${ }^{1,2 *}$, Adrian Marchetti ${ }^{1+}$, Justin B. Ries ${ }^{2 \dagger}$ and Karl D. Castillo ${ }^{1}$ \\ ${ }^{1}$ Department of Marine Sciences, University of North Carolina at Chapel Hill, Chapel Hill, NC, USA, ${ }^{2}$ Department of Marine \\ and Environmental Sciences, Northeastern University, Nahant, MA, USA
}

The oceans are becoming warmer and more acidic as a result of rising atmospheric $\mathrm{pCO}_{2}$. Transcriptome plasticity may facilitate marine organisms' acclimation to thermal and acidification stress by tailoring gene expression to mitigate the impacts of these stressors. Here, we produce the first transcriptome of the abundant, ubiquitous, and resilient Caribbean reef-building coral Siderastrea siderea, and investigate this corals' transcriptomic response to 95 days of thermal $\left(T=25,28,32^{\circ} \mathrm{C}\right)$ and $\mathrm{CO}_{2}$-induced acidification (324, 477, 604, $2553 \mu \mathrm{atm})$ stress. The S. siderea transcriptome was assembled using RNAseq and then Weighted Gene Correlation Network Analysis was employed to obtain systems-level insights into the coral's stress response. Exposure of the coral to both elevated temperature and acidification elicited strong but divergent transcriptomic responses. Gene Ontology analysis suggests that long-term thermal stress disrupts homeostasis by increasing transcription of protein-coding genes associated with protein catabolism and suppressing transcription of genes involved in responding to environmental stimuli. Both next century (604 $\mu \mathrm{atm})$ and extreme-high (2553 $\mu \mathrm{atm}) \mathrm{pCO}_{2}$ stress increased transcription of genes associated with respiration, highlighting the potentially greater energetic requirements of maintaining calcification under high- $\mathrm{pCO}_{2}$ conditions. Under extreme-high- $\mathrm{CCO}_{2}$, increased transcription of $\mathrm{H}^{+}$-transporter genes was observed, consistent with the proposed role of proton transport in facilitating coral calcification under elevated $\mathrm{pCO}_{2}$. These results suggest that 95 days of exposure to $32^{\circ} \mathrm{C}$ seawater elicits a more adverse transcriptomic response (i.e., broad scale reductions in gene expression) than exposure to extreme-high acidification (2553 $\mu \mathrm{atm}$; i.e., increased expression of genes associated with ion transport) within S. siderea - with the response to extreme warming suggesting cellular shutdown and the response to extreme acidification indicating capacity for acclimation. These results are consistent with the observation that rates of net calcification for the investigated corals were more negatively affected by the prescribed thermal stress than by the prescribed acidification stress. This study demonstrates how transcriptome plasticity may promote coral acclimation to these global change stressors, but that there are limits to the efficacy of this plasticity.

Keywords: climate change, ocean acidification, thermal stress, coral, transcriptome, Siderastrea siderea, proton pump, WGCNA 


\section{INTRODUCTION}

The partial pressure of atmospheric carbon dioxide $\left(p \mathrm{CO}_{2}\right)$ has increased from $280 \mu \mathrm{atm}$ to levels exceeding $400 \mu \mathrm{atm}$ since the Industrial Revolution in the mid-eighteenth century (Doney et al., 2009). Over the last 100 years, increasing atmospheric $p \mathrm{CO}_{2}$ has elevated mean sea surface temperatures (SST) by $0.7^{\circ} \mathrm{C}$ and reduced mean seawater $\mathrm{pH}$ by 0.1 (Bindoff et al., 2007). It is predicted that atmospheric $p \mathrm{CO}_{2}$ will surpass $700 \mu \mathrm{atm}$ by the end of the twenty-first century, resulting in additional $\mathrm{CO}_{2}$-induced warming and ocean acidification (Doney et al., 2012). Along with other marine organisms, reef-building corals have already experienced the negative effects of these $\mathrm{CO}_{2}$ induced stressors, with annual episodes of "coral bleaching" (i.e., breakdown of the coral-algae symbiosis) predicted to affect all reefs by the year 2040 (van Hooidonk et al., 2013) and increased SST and $p \mathrm{CO}_{2}$ projected to impair coral calcification and reef accretion (Hoegh-Guldberg et al., 2007).

The phenotypic responses of marine calcifiers to both increased temperature and acidification have been well characterized and responses vary widely across species (Ries et al., 2009; Pandolfi, 2015) and populations (Dixon et al., 2015). Reef-construction by scleractinian corals provides numerous ecological services and is integral to maintaining health of the entire reef ecosystem (Moberg and Folke, 1999). Therefore, even small reductions in coral calcification rates have the potential to disrupt the balance of accretion and erosion on reefs, which can negatively affect their ecological function (Chan and Connolly, 2013). Numerous studies have documented reductions in coral calcification in response to both low and high temperature (Cooper et al., 2008; De'Ath et al., 2009; Kenkel et al., 2013a; Castillo et al., 2014) and $p \mathrm{CO}_{2}$ (Langdon and Atkinson, 2005; Doney et al., 2009; Kleypas and Yates, 2009; Chan and Connolly, 2013; Castillo et al., 2014). However, over the range of $p \mathrm{CO}_{2}$ and temperatures predicted for the next several centuries, increased temperatures have been shown to cause a greater decline in coral calcification rate than increased $p \mathrm{CO}_{2}$ (Chua et al., 2013; Castillo et al., 2014).

The transcriptomic response of corals to short-term (hoursdays) temperature stress consistently includes regulation of heatshock proteins, apoptosis pathways, and genes associated with ion transport and metabolism (Meyer et al., 2011; Barshis et al., 2013; Dixon et al., 2015), with longer-term thermal stress causing broad-scale downregulation of basic metabolic processes (Vidal-Dupiol et al., 2014). The coral transcriptomic response to $\mathrm{CO}_{2}$-induced acidification has received far less attention, with existing studies focused on relatively short-term exposures of 3 days (Moya et al., 2012), 9 days (Moya et al., 2015), 3 weeks (Vidal-Dupiol et al., 2013), and 28 days (Kaniewska et al., 2012), and with somewhat conflicting outcomes. Moya et al. (2012) observed metabolic suppression and enhancement of extracellular skeletal organic matrix in Acropora millepora recruits exposed to elevated $p \mathrm{CO}_{2}$ (750 and $\left.1000 \mu \mathrm{atm}\right)$ for 3 days. However, this response was not maintained in 9-day experiments on conspecifics where, in contrast to the 3-day study, anti-apoptotic genes were upregulated (Moya et al., 2015). In a 28-day $p \mathrm{CO}_{2}$ stress experiment on adult $A$. millepora
(Kaniewska et al., 2012), the transcriptomic response was consistent with the metabolic impairment observed in the Moya et al. (2012) study. A 21-day experiment on adult Pocillopora damicornis revealed increased expression of genes encoding for ion-transport and energy-production proteins, suggesting increased metabolic demands under elevated $p \mathrm{CO}_{2}$ (VidalDupiol et al., 2013). These contrasting responses to $p \mathrm{CO}_{2}$ may reflect taxonomic differences, differences in the time scale of the investigation, and/or differences in nutritional status and/or environmental histories of the investigated specimens. Indeed the majority of studies have focused on the emerging coral model A. millepora (Kaniewska et al., 2012; Moya et al., 2012, 2015), which is highly genetically divergent from corals in other lineages (Kitahara et al., 2010), making it difficult to extrapolate results to other species of reef-building corals.

Despite the inconsistencies observed in corals' transcriptomic responses to $p \mathrm{CO}_{2}$ stress, the general repertoire of responses appears to contrast that of the responses of corals to elevated temperature. However, in order to directly investigate how these transcriptomic responses differ across stressors, a comparative study explicitly testing these stress responses in parallel is required. Although corals may experience these stressors in tandem, it is essential to conduct experiments that isolate the effects of these stressors on the same time scale in order to identify the mechanisms by which they may impact coral calcification in the future.

Castillo et al. (2014) recently demonstrated that $S$. siderea exhibits parabolic calcification responses to both warming and acidification, whereby moderately elevated temperature and $p \mathrm{CO}_{2}$ enhanced calcification and extremely elevated temperature and $p \mathrm{CO}_{2}$ impaired calcification (Figure 1). Despite the consistent parabolic shape of the corals' calcification responses to both stressors, the prescribed warming (32 vs. $28^{\circ} \mathrm{C}$ ) was shown to have a much more adverse impact on net calcification rates $(80 \%$ decrease relative to control treatment) than the prescribed increase in $\mathrm{pCO}_{2}$ (2553 vs. $477 \mu \mathrm{atm}$-resulting in only $25 \%$ decrease in net calcification relative to control). In the present study, transcriptomic
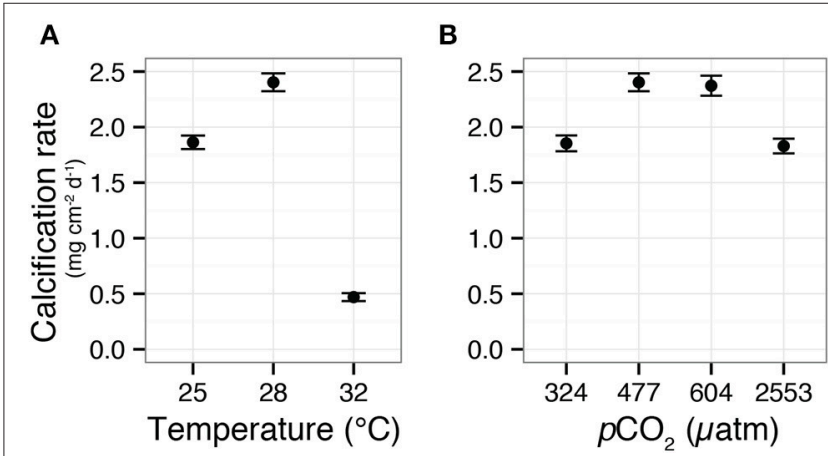

FIGURE 1 | Calcification responses of the coral Siderastrea siderea to elevated $p \mathrm{CO}_{2}$ and temperature across a 95-day experiment. Mean $\left( \pm\right.$ SE) coral calcification rates in temperatures of 25,28 , and $32^{\circ} \mathrm{C}$ (A). Mean ( \pm SE) coral calcification rates at $p \mathrm{CO}_{2}$ of $324,477,604$, and $2553 \mu \mathrm{atm}$ (B). Figure modified from Castillo et al. (2014). 
profiles of the same coral specimens from the Castillo et al. (2014) study were generated using RNAseq. Gene expression patterns were explored across three temperature and four $p \mathrm{CO}_{2}$ treatments to investigate the molecular underpinnings of this coral's differential calcification responses to ocean acidification (i.e., milder response) and warming (i.e., stronger response; Table 1).

Temperature treatments include the coral's in situ monthly minimum $\left(25^{\circ} \mathrm{C}\right)$, mean (control: $28^{\circ} \mathrm{C}$ ), and maximum temperature $\left(32^{\circ} \mathrm{C}\right)$, all maintained at approximately the same $p \mathrm{CO}_{2}$ (ca. $\left.488 \mu \mathrm{atm}\right)$. The $p \mathrm{CO}_{2}$ treatments include preindustrial $(324 \mu \mathrm{atm})$, near present-day (control: $477 \mu \mathrm{atm})$, next-century (604 $\mu \mathrm{atm})$, and extreme-high $p \mathrm{CO}_{2}(2553 \mu \mathrm{atm})$, all maintained at approximately the same temperature $\left(28^{\circ} \mathrm{C}\right)$. The reef-building coral Siderastrea siderea is an ideal candidate for investigating the transcriptomic response of corals to global change stressors because it is abundant and ubiquitously distributed throughout the Caribbean basin (Veron, 2000), inhabits a wide spectrum of habitats spanning broad $\mathrm{pH}$ and temperature ranges (Lirman and Fong, 2007), is a robust species shown to be highly tolerant of chronic stress (Colella et al., 2012; Castillo et al., 2014) and, despite its ecological importance, remains relatively unexplored from a genomic perspective.

The reference transcriptome for S. siderea was assembled from RNAseq data. A Weighted Gene Coexpression Network Analysis (WGCNA; an established method for investigating pathway-level transcriptomic responses; Dixon et al., 2015; Rose et al., 2016) was employed to acquire systems-level insights into the corals' transcriptomic responses to the treatment conditions. This study was designed to isolate and compare the transcriptomic responses of S. siderea to thermal and $p \mathrm{CO}_{2}$ stress and assess potential linkages between the resulting gene expression profiles and the differential calcification responses previously observed in response to these two stressors.

\section{MATERIALS AND METHODS}

\section{Experimental Design}

Detailed descriptions of the experimental design are available in Castillo et al. (2014) and the specific parameters of the experimental treatments (temperature, salinity, $\mathrm{pH}$, total alkalinity, dissolved inorganic carbon, $p \mathrm{CO}_{2}$ of the mixed gases in equilibrium with the experimental seawaters, carbonate ion concentration, bicarbonate ion concentration, dissolved carbon dioxide, and aragonite saturation state) can be found in the supplementary information of Castillo et al. (2014). In brief, six colonies of $S$. siderea from nearshore environments and six colonies from forereef environments were collected in July 2011 from the Belize Mesoamerican Barrier Reef and immediately transported to the University of North Carolina (UNC) Aquarium Research Center. Colonies were sectioned into 18 fragments, which were maintained in one of six experimental treatments ( 3 replicate tanks per treatment) for 95 days.

Partial pressures of $\mathrm{CO}_{2}$ (standard deviation: SD) of 324 (89), 477 (83), 604 (107), and 2553 (506) $\mu \mathrm{atm}$ were employed to correspond to near-pre-industrial, near-present-day, predicted end-of-century, and an extreme year 2500 scenario (the latter to investigate how S. siderea responds to seawater that is undersaturated with respect to aragonite). Seawater temperatures (SD) of $25.01(0.14), 28.16(0.24)$, and $32.01(0.17)^{\circ} \mathrm{C}$ were employed to approximate monthly minimum, mean, and maximum seawater temperatures over the past 10 years (20022012) as determined from in situ seawater temperature records obtained near the coral collection sites (Castillo and Helmuth, 2005; Castillo and Lima, 2010; Castillo et al., 2012), and also to encompass the range of average annual seawater temperatures predicted for the next century. All experimental tanks were illuminated with a conservative irradiance of $250 \mu \mathrm{mol}$ photons $\mathrm{m}^{-2} \mathrm{~s}^{-1}$ on a 12-h light-dark cycle in order to minimize potential light stress that could confound the corals' responses

TABLE 1 | Summary of RNA libraries including the number of individual nubbins from which RNA was pooled, reef zone where corals were collected (forereef $=$ "FR" and nearshore $=$ "NS"), temperature $\left({ }^{\circ} \mathrm{C}\right) \pm \mathrm{SD}, p \mathrm{CO}_{2}$ ( $\mu$ atm) $\pm \mathrm{SD}$, and total number of raw 100 bp paired-end ("PE") reads sequenced with Illumina Hiseq 2000.

\begin{tabular}{|c|c|c|c|c|c|}
\hline Sample & \# Pooled & Reef zone & Temperature $\left({ }^{\circ} \mathrm{C}\right) \pm \mathrm{SD}$ & $p \mathrm{CO}_{2}(\mu \mathrm{atm}) \pm \mathrm{SD}$ & \# PE Reads \\
\hline T1 & 6 & FR & $28.14 \pm 0.27$ & $324 \pm 89$ & $63,562,692$ \\
\hline T2 & 6 & FR & $28.04 \pm 0.28$ & $604 \pm 107$ & $77,118,516$ \\
\hline T4 & 6 & NS & $28.14 \pm 0.27$ & $324 \pm 89$ & $88,325,197$ \\
\hline T5 & 8 & NS & $28.04 \pm 0.28$ & $604 \pm 107$ & $48,502,771$ \\
\hline T8 & 14 & $\mathrm{FR}$ & $28.16 \pm 0.24$ & $477 \pm 83$ & $63,231,049$ \\
\hline T9 & 9 & $\mathrm{FR}$ & $32.01 \pm 0.17$ & $472 \pm 86$ & $49,982,878$ \\
\hline T10 & 7 & NS & $25.01 \pm 0.17$ & $515 \pm 92$ & $99,991,483$ \\
\hline T11 & 7 & NS & $28.16 \pm 0.24$ & $477 \pm 83$ & $56,682,470$ \\
\hline T12 & 7 & NS & $32.01 \pm 0.17$ & $472 \pm 86$ & $54,685,454$ \\
\hline
\end{tabular}


to the prescribed treatments (Supplementary Figure 1). Coral tissue was removed with a seawater sprayer (WaterPik) at the completion of the experiment, immediately preserved in RNAlater, and stored at $-80^{\circ} \mathrm{C}$ until RNA isolation.

\section{RNA Isolation and Sequencing Preparation}

To achieve a sufficient quantity of RNA for sequencing, RNA was isolated from a total of 94 individual nubbins and then pooled by reef environment within each experimental treatment, yielding a total of 12 sequencing libraries (Table 1), each of which contained the RNA of at least six individuals. RNA pooling within treatments was necessary due to low RNA quantity per individual and is generally regarded as appropriate when the primary objective is to examine population-level, rather than individual-level, characteristics (Kendziorski et al., 2003). The nearshore and forereef pools within each treatment were individually sequenced and, therefore, considered biological replicates (Kendziorski et al., 2003) - a replication scheme that is accepted in transcriptomic studies (Daniels et al., 2015).

Coral RNA was isolated with the ToTALLY RNA Kit (Ambion) using the manufacturer's protocol with some additional steps. Prior to RNA extraction, samples were thawed on ice and centrifuged at $8000 \mathrm{rpm}$ for $1 \mathrm{~min}$. The RNA-later was then decanted and replaced with $500 \mathrm{uL}$ lysis buffer along with a small amount of glass beads. Samples were then placed in a bead beater for $1 \mathrm{~min}$ and centrifuged again at 8000 $\mathrm{rpm}$ for $1 \mathrm{~min}$ before proceeding with the manufacturer's protocol. Trace DNA contamination was eliminated by DNase 1 (Ambion) digestion at $37^{\circ} \mathrm{C}$ for $45 \mathrm{~min}$. Library preparation, including a poly $(\mathrm{A})^{+}$-selection to obtain eukaryotic mRNA, cDNA normalization, and sequencing were completed at the UNC High Throughput Sequencing Facility (UNC-HTSF). Twelve pooled libraries were prepared using poly $(\mathrm{A})^{+}$-selection and sequencing was performed using two lanes of Illumina HiSeq 2000 at the UNC-HTSF, which yielded paired-end (PE) $100 \mathrm{bp}$ reads (Table 2). Technical replicates of each lane were then resequenced to increase depth of coverage, yielding a total of four lanes of Illumina HiSeq 2000.

\section{Transcriptome Assembly}

For transcriptome assembly purposes, all sequencing data were pooled, yielding over 770 million PE reads. Fastx_toolkit trimmed Illumina TruSeq adapters and poly $(\mathrm{A})^{+}$tails using the fastx_clipper function. Sequences $<50$ bp in length were removed for assembly purposes. Resulting reads were then quality filtered using fastq_quality_filter with the requirement that $\geq 80 \%$ of bases meet a cutoff score of 20 . Reads were repaired and data redundancy was removed using fastx_collapser. Collapsed files then served as input for RNAseq de novo assembly using Trinity (Grabherr et al., 2011) with 750 GB of system memory and $24 \mathrm{CPUs}$ at the Texas Advanced Computing Center (TACC) at the University of Texas at Austin.

\section{Separation of Host- and Symbiont-Derived Contigs}

All currently available (as of November 2014) Symbiodinium and cnidarian transcriptomes and genomes were obtained from public databases and assembled into four distinct databases (Table 3; Putnam et al., 2007; Zhang et al., 2007; Shinzato et al., 2011; Bayer et al., 2012; Ladner and Palumbi, 2012; Lehnert et al., 2012; Moya et al., 2012; Barshis et al., 2013; Kenkel et al., 2013b; Shoguchi et al., 2013; Wright et al., 2015). These databases were (1) all available cnidarian data $(N=23)$, (2) all available Symbiodinium data $(N=15)$, (3) aposymbiontic cnidarian data only $(N=14)$, and (4) cultured Symbiodinium data only $(N=6)$. Databases were indexed and a translated blast search (tblast $x$ ) of the Trinity-assembled transcriptome was completed against each of the four databases. A contig was considered a host contig if it had an amino acid (AA) length overlap greater than $100 \mathrm{bp}$ with a $75 \%$ identity cutoff to any

TABLE 2 | Summary of sequence mapping details, including reef zone from where corals were collected (forereef = "FR" and nearshore = "NS"), temperature ("T," ${ }^{\circ} \mathrm{C}$ ), $\mathrm{pCO}_{2}$ ( $\mu$ atm), total number of raw 100 bp paired-end (PE) reads sequenced with Illumina Hiseq 2000 ("\# PR Reads"), millions of unpaired reads remaining after trimming and quality control ("Trimmed"), millions of reads that mapped to the holobiont transcriptome ("Mapped"), and total millions of mapped S. siderea reads ("Host").

\begin{tabular}{|c|c|c|c|c|c|c|c|}
\hline Sample & Reef zone & $\mathbf{T}$ & $p \mathrm{CO}_{2}$ & \# PE reads & Trimmed (million) & Mapped (million) & Host (million) \\
\hline FR_P324 & FR & 28 & 324 & $63,562,692$ & 104.0 & 59.2 & 6.5 \\
\hline FR_P604 & FR & 28 & 604 & $77,118,516$ & 128.4 & 72.3 & 19.0 \\
\hline FR_P2553 & FR & 28 & 2553 & $48,145,112$ & 78.7 & 44.7 & 5.9 \\
\hline NS_P324 & NS & 28 & 324 & $88,325,197$ & 145.0 & 82.4 & 8.5 \\
\hline NS_P604 & NS & 28 & 604 & $48,502,771$ & 80.6 & 45.3 & 12.1 \\
\hline NS_P2553 & NS & 28 & 2553 & $69,157,311$ & 114.0 & 64.6 & 10.1 \\
\hline FR_T25 & FR & 25 & 515 & $50,943,566$ & 81.5 & 47.4 & 3.9 \\
\hline FR_Control & FR & 28 & 477 & $63,231,049$ & 101.1 & 58.8 & 5.4 \\
\hline FR_T32 & FR & 32 & 472 & $49,982,878$ & 82.6 & 47.2 & 21.7 \\
\hline NS_T25 & NS & 25 & 515 & $99,991,483$ & 160.0 & 93.1 & 8.4 \\
\hline NS_Control & NS & 28 & 477 & $56,682,470$ & 90.3 & 52.7 & 4.1 \\
\hline NS_T32 & NS & 32 & 472 & $54,685,454$ & 89.7 & 51.5 & 19.7 \\
\hline
\end{tabular}


TABLE 3 | Summary of mapping databases used to determine whether a contig originated from Siderastrea siderea or Symbiodinium.

\begin{tabular}{|c|c|c|}
\hline Reference & Database & Source \\
\hline Acropora hyacinthus & Coral & Barshis et al., 2013 \\
\hline A. hyacinthus larvae & Coral, apo-coral & Wright et al., 2015 \\
\hline Acropora digitifera & Coral, apo-coral & Shinzato et al., 2011 \\
\hline Anthopleura elegantissima & Coral & Meyer, unpublished \\
\hline A. millepora & Coral & Moya et al., 2012 \\
\hline Acropora tenuis & Coral, apo-coral & Matz, unpublished \\
\hline Fungia scrutaria & Coral & Meyer, unpublished \\
\hline Madracis auretenra & Coral & Meyer, unpublished \\
\hline Montastraea cavernosa & Coral & Meyer, unpublished \\
\hline Nematastella vectensis & Coral, apo-coral & Putnam et al., 2007 \\
\hline Porites Astreoides & Coral & Kenkel et al., 2013b \\
\hline Pseudodiploria strigosa & Coral, apo-coral & Meyer, unpublished \\
\hline Seriatopora hystrix & Coral & Meyer, unpublished \\
\hline Aiptasia & Coral, apo-coral & Lehnert et al., 2012 \\
\hline Clade A & Sym, cul-sym & Bayer et al., 2012 \\
\hline Clade B & Sym, cul-sym & Bayer et al., 2012 \\
\hline D1a_mont & Sym & Lajeunesse, MMETSP1377 \\
\hline SymbB1a, SymbB1_trinity & Sym, cul-sym & Shoguchi et al., 2013 \\
\hline SymC & Sym & Ladner et al., 2012 \\
\hline SymD & Sym & Ladner et al., 2012 \\
\hline A_Tridactna & Sym & Gates, MMETSP1374 \\
\hline C_15_Porites (1-2) & Sym & Gates, MMETSP1370, 1371 \\
\hline C1_tenuis (1-2) & Sym & Gates, MMETSP1367, 1369 \\
\hline CAM_ASM & Sym, cul-sym & Zhang et al., 2007 \\
\hline freeliving (1-4) & Sym, cul-sym & $\begin{array}{l}\text { MMETSP1110, 1115, } 1116 \text {, } \\
1117\end{array}$ \\
\hline Palau_free (1-4) & Sym, cul-sym & $\begin{array}{l}\text { MMETSP1122, 1123, } 1124 \text {, } \\
1125\end{array}$ \\
\hline mf105_CladeB & Sym, cul-sym & Medina, unpublished \\
\hline Kb8_CladeA & Sym, cul-sym & Medina, unpublished \\
\hline
\end{tabular}

"Coral" indicates all available cnidarian data and "sym" indicates all available Symbiodinium data, "apo-coral" indicates cnidarian references in aposymbiotic form only, and "cul-sym" indicates cultured Symbiodinium data only.

cnidarian. However, if the same contig was also assigned to cultured Symbiodinium with a 100 bp AA overlap with $80 \%$ identity, it was removed from the host transcriptome. Lower threshold identity (75\%) was used for the host when compared to Symbiodinium (80\%) since, at the time of sequencing, no sequences were available for Siderastrea spp. Symbiodinium contigs were assigned in the same manner as described above and contigs were removed if they also assigned to aposymbiotic cnidarians with 100 bp AA overlap and 80\% identity. If a contig was present in host and symbiont transcriptomes after filtering, this contig was removed from both transcriptomes. In addition, any contigs in the host transcriptome annotated as being chloroplast-associated genes were removed. Lastly, ribosomal RNA contamination was identified as sequences exhibiting significant nucleotide similarity (BLASTN, $e$-value $\leq 1 \times 10^{-8}$ ) to the SILVA LSU and SSU rRNA databases (http://www.arb-silva.de/). A total of three contigs from the Siderastrea siderea transcriptome, each of which matched a coral-specific rRNA, were identified using this approach and were removed from the database.

\section{Siderastrea siderea Transcriptome Annotation}

Cnidarian-specific contigs were annotated by BLAST sequence homology searches against UniProt and Swiss-Prot NCBI NR protein databases with an $e$-value cutoff of $\mathrm{e}^{-5}$ and annotated sequences were then assigned to Gene Ontology (GO) categories (Consortium, 2015). Metrics of transcriptome contiguity and Core Eukaryotic Genes Mapping Approach (CEGMA) were employed to gauge transcriptome completeness. Contiguity determines the percentage of expressed reference transcripts covered by the longest assembled transcript (i.e., protein coverage) and CEGMA assesses the proportion of core eukaryotic genes (CEGs) from an unbiased set of proteins expressed and conserved within eukaryotes (Parra et al., 2007).

\section{Read Mapping and Differential Gene Expression Analysis}

Read mapping and differential gene expression were first compared across the technical sequencing replicates to investigate lane effects. No differences were observed in numbers of isogroups or numbers of differentially expressed genes (DEGs). Therefore, lane replicates were combined for final analysis. Raw reads across libraries ranged from 48.1 to 100.0 million PE 100 bp sequences (Table 1). Fastx_toolkit was used to remove Illumina TruSeq adapters and poly(A) ${ }^{+}$tails. Sequences $<20$ bp in length with $<90 \%$ (10\% more stringent than trimming threshold used for transcriptome assembly) of bases having quality cutoff scores $>20$ were also trimmed. The resulting quality filtered reads ( $\mathrm{R} 1$ and unpaired reads only) were then mapped to the holobiont transcriptome (Siderastrea siderea + Symbiodinium) using Bowtie2.2.0 (Langmead and Salzberg, 2012). Total counts of S. siderea mapped reads ranged from 3.9 (FR_T25) to 21.7 (FR_32) million with holobiont mapping efficiencies ranging from 46.0 to 52.9\% (Table 2 and Supplementary Data Sheet 1).

Differential gene expression analyses were performed with DESeq2 v. 1.6.3 (Love et al., 2014) in R v. 3.1.1 (R Development Core Team, 2015). Expression data were normalized using the rlog function, which is a robust normalization method when size factors vary across samples (Love et al., 2014). First, all normalized data ( $N=16,931$ genes) were subjected to a principle coordinate analysis to visualize the overall transcriptomic differences of all transcriptomic samples using the pcoa function in the $\mathrm{R}$ package vegan. Then, independent differences between treatments and reef sites were tested using the Adonis function (Oksanen et al., 2013). Second, a subset of these genes (FDR adjusted $p<0.05$ for any treatment, described below, $N=7242$ genes) was subjected to the same analysis. Pooled libraries from both environments within a treatment yielded similar expression data (described in results) and were therefore treated as biological replicates.

Numbers of DEGs were determined using the model: design $\sim$ reef zone + treatment. First, counts were normalized and then 
independent pairwise contrasts were computed independently for each treatment relative to the control. Genes identified as differentially expressed were then corrected for false positives using the Benjamini and Hochberg false discovery rate (FDR) correction for multiple testing (Benjamini and Hochberg, 1995). A contig was considered significantly differentially expressed if it had an average basemean expression $>5$ and it had an FDR adjusted $p<0.05$. Because environment was explicitly modeled, dispersion estimates should reduce the discovery of DEGs within each treatment if genes of corals from the two environments express differently, thereby maintaining a conservative statistical approach.

\section{Weighted Gene Co-expression Network Analysis}

The primary objective of this study is to investigate the effects of thermal and acidification stress on full molecular pathways within corals, rather than on the expression of individual genes. Correlation structure in the expression data was therefore examined using a systems genetics approach, in which all rlog-transformed genes were subjected to Weighted Gene Coexpression Network Analysis (WGCNA) (Langfelder and Horvath, 2008). This methodology identifies groups of genes ("modules") that are co-regulated within treatments across experimental samples. Although appropriate for interpreting the results of the present study, it should be noted that this systems level analysis may not yield outcomes that are directly comparable to those generated from traditional gene expression analysis.

The expression of genes in these modules can be summarized by the overall module expression profile, which is represented by the module's eigengene. This eigengene expression can then be correlated post-hoc with treatment conditions ("traits"). Gene significance is defined as the absolute value of the correlation between individual genes within a module and the treatment condition of interest, while module membership represents the correlation of the individual gene's expression with the module eigengene (Langfelder and Horvath, 2008). Here, correlations with experimental treatment condition were assessed to identify modules that capture entire co-expressed pathways correlating with the corals' stress responses to temperature and $p \mathrm{CO}_{2}$. Data were visualized using heatmaps of all genes within individual libraries, along with overall eigengene expression of that library for the specific module of genes, in order to explore the expression patterns of individual genes within each module.

\section{Module Gene Ontology (GO) Enrichment}

A typical "GO enrichment" analysis based on Fisher's exact tests was applied to the statistically conservative binary (presence/absence) measure of a gene's presence within a WGCNA module to identify GO enrichment within that module. Results were then plotted as a dendrogram, which traces the level of gene sharing between significant GO categories and lists the number of genes represented in the module over the total number of genes assigned to each category within the entire expression dataset (Dixon et al., 2015).

\section{RESULTS}

\section{Siderastrea siderea Transcriptome}

The investigation of gene expression differences across treatments first required the assembly of a complete reference transcriptome for $S$. siderea. After adapter trimming and quality filtering, a total of $1,255,626,250$ reads were retained (81.5\%), of which 536,426,960 were paired (69.6\%) and $182,772,330$ were unpaired (11.9\%). A total of 333,835 contigs ( $\mathrm{N} 50=$ 1673) were in the assembled holobiont metatranscriptome, of which 46,387 were unambiguously assigned as $S$. siderea specific contigs, with an average length of $2236 \mathrm{bp}$ and an N50 of 2753. Among host contigs, 16,931 unique isogroups were obtained, of which 12,088 (71.4\%) had gene annotations based on sequence homology. Forty-seven percent of $S$. siderea contigs had protein coverage exceeding 0.75 (Supplementary Figure 2) and results from the Core Eukaryotic Genes Mapping Approach (CEGMA; (Parra et al., 2007) suggest that $73.3 \%$ of complete highly conserved core genes were present (77.1\% partially complete), indicating that the transcriptome was comprehensive. All raw reads are archived in the National Center for Biotechnology Information Short Read Archive (SRA) under accession number PRJNA307543, with transcriptome assembly and annotation files available at https://sarahwdavies.wordpress.com/data/ and www.bco-dmo.org/project/635863.

\section{S. siderea Transcriptomic Responses to Temperature and $\mathrm{pCO}_{2}$}

RNAseq analysis revealed that the effect of reef site was insignificant when comparing both the entire transcriptome (Adonis $p_{\text {site }}=0.055$, Supplementary Figure 3 ) and the DEG data subset (Adonis $p_{\text {site }}=0.079$, Figure 2C), supporting the use of these pooled RNA libraries as biological replicates. Instead, strong associations were observed between expression levels of transcripts within each of the six treatments, regardless of reef environment. These treatment-specific responses held for both the entire transcriptome (Adonis ptreatment $<0.001$, Supplementary Figure 3 ) and the DEG data subset (Adonis $p_{\text {treatment }}<0.001$, Figure $2 \mathrm{C}$ ), suggesting that each treatment elicited a distinct stress response. Relative to control conditions $\left(p \mathrm{CO}_{2}=477 \mu \mathrm{atm}, 28^{\circ} \mathrm{C}\right), 1.1,12.0$, and $5.5 \%$ of $S$. siderea genes were identified as differentially expressed under low (324 $\mu \mathrm{atm})$, high (604 $\mu \mathrm{atm})$, and extreme-high (2553 $\mu \mathrm{atm})$ $p \mathrm{CO}_{2}$ conditions, respectively, while $2.9 \%$ and $18.2 \%$ of genes were identified as differentially expressed under 25 and $32^{\circ} \mathrm{C}$, respectively (Figures 2A,B; Supplementary Data Sheets 2-6). Notably, the majority (72.3\%) of DEGs in the high-temperature treatment $\left(32^{\circ} \mathrm{C}\right)$ were underrepresented relative to the control, far more than under the extreme-high $\mathrm{pCO}_{2}$ treatment (48\%; Figures 2A,B). Importantly, these results suggest that the thermal stress investigated in this study $\left(32^{\circ} \mathrm{C}\right)$ had a more adverse impact on the coral (i.e., greater proportion of underrepresented genes) than the extreme acidification stress (2553 $\mu \mathrm{atm}$; i.e., greater proportion of overrepresented genes)-consistent with observed $c a .80 \%$ reduction in net calcification rate (relative to the control) at $32^{\circ} \mathrm{C}$ vs. the ca. $25 \%$ reduction observed at $2553 \mu \mathrm{atm}$ (Figure 1; Castillo et al., 2014). 


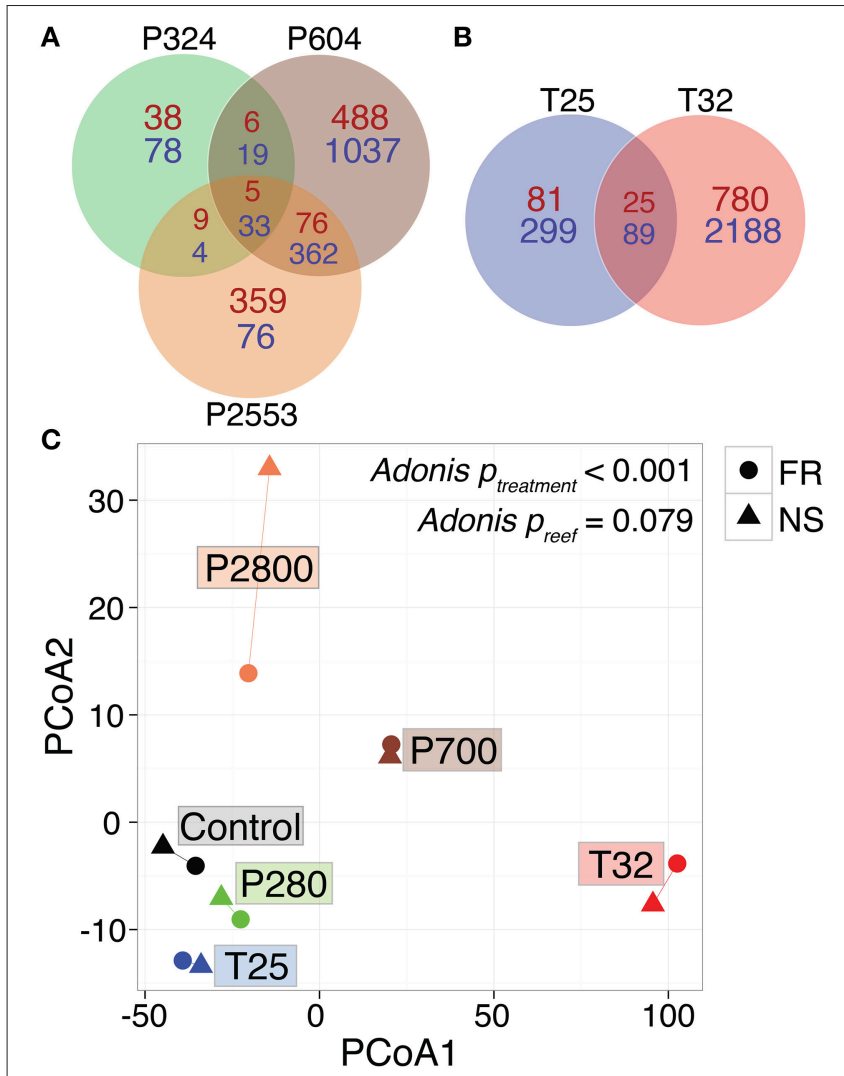

FIGURE 2 | Global RNA-Seq patterns for Siderastrea siderea under various temperature and $\mathbf{p} \mathbf{C O}_{\mathbf{2}}$ treatments. Venn diagram of differentially expressed genes in Siderastrea siderea $(F D R=0.05)$, with respect to $\mathrm{pCO}_{2}$ treatments $(\mathbf{A})$ and temperature treatments $(\mathbf{B})$ relative to the control treatment $\left(\mathrm{pCO}_{2}=477 \mu \mathrm{atm}, 28^{\circ} \mathrm{C}\right)$. Red numbers indicate overrepresented genes and blue numbers indicate underrepresented genes. (C) Principal coordinate analysis (PCoA) of all r-log transformed isogroups passing the FDR-corrected $p<0.05$ threshhold clustered by experimental treatment, demonstrating significantly different transcriptomic responses of corals across different experimental treatments, regardless of reef zone origin ("NS" = nearshore and "FR" = forereef; Adonis $p_{\text {treatment }}<0.001$, Adonis $\left.p_{\text {site }}=0.0779\right)$. Symbol colors represent treatment conditions: black = control: $\left(477 \mu \mathrm{atm}, 28^{\circ} \mathrm{C}\right)$, green $=$ low $\mathrm{pCO}_{2}\left(324 \mu \mathrm{atm}, 28^{\circ} \mathrm{C}\right)$, brown $=$ high $p \mathrm{CO}_{2}\left(604 \mu \mathrm{atm}, 28^{\circ} \mathrm{C}\right)$, orange $=$ extreme-high $\mathrm{pCO}_{2}\left(2553 \mu \mathrm{atm}, 28^{\circ} \mathrm{C}\right)$, blue $=$ low temperature $\left(515 \mu \mathrm{atm}, 25^{\circ} \mathrm{C}\right)$, and red $=$ high temperature $\left(472 \mu \mathrm{atm}, 32^{\circ} \mathrm{C}\right)$.

Differential gene expression information for each treatment is included in Supplementary Data Sheets 2-6.

\section{Treatment-Specific Transcriptomes Show Overrepresentation of Distinct Pathways}

The WGCNA assigned all 16,931 rlog-transformed isogroups to seven co-expression modules (designated by colors) with a module merging of 0.6 , which effectively merged modules with highly correlated eigengenes (Figure 3A). Four module eigengenes were significantly correlated with distinct stressors (Figure 3): "blue" (679 genes) and "turquoise" (3919 genes) modules correlated with extreme temperature $\left(32^{\circ} \mathrm{C}\right)$ $\left(\mathrm{r}_{\text {blue }}=0.98, \mathrm{r}_{\text {turquoise }}=-0.91\right)$, while "green" (4871 genes, $\left.\mathrm{r}_{\text {green }}=0.79\right)$ and "purple" modules (1648 genes, $\left.\mathrm{r}_{\text {purple }}=0.86\right)$ correlated with high $(604 \mu \mathrm{atm})$ and extreme-high (2553 $\mu \mathrm{atm})$ $p \mathrm{CO}_{2}$, respectively (Figures 3B,C). Correlations between gene significance and module membership were used to further substantiate these relationships, with correlations ranging from 0.61 for the (purple) module to 0.97 for the "blue" module (Figure 3C). No modules were significantly correlated with low temperature $\left(25^{\circ} \mathrm{C}\right)$ and the only module correlating with low $p \mathrm{CO}_{2}(324 \mu \mathrm{atm})$ was the "gray" module, which only contained 47 genes, a number too small for system-level analyses.

Gene Ontology (GO) enrichment analysis of the overrepresented genes in the "blue" module correlating to the extreme temperature treatment found no enrichment of any GO terms for "cellular compartment" (CC). However, within the "biological process" (BP) GO category enrichment of many metabolism and catabolism pathways was observed (Figure 4A). These GO terms were often specifically associated with the breakdown of amino acids (i.e., cellular amino acid catabolic process; GO:0009063). Gene Ontology enrichment of the "blue" module also detected mild enrichment of oxidoreductase activity in the "molecular function" (MF) category (oxidoreductase, acting on the $\mathrm{CH}-\mathrm{NH}$ group of donors; GO:0016645); however, this GO term was only marginally significant $(p<0.10$; Figure 4A).

Gene Ontology enrichment of the highly underrepresented module for $32^{\circ} \mathrm{C}$ ("turquoise"), which contained 3919 genes, detected many significant GO terms across all GO categories (CC, BP, MP; Figure 4B). Gene Ontology terms within CC and BP included many GO terms associated with cilia [e.g., cilium (GO:0005929) and cell projection (GO:0042995)] and synaptic activity [e.g., synaptic membrane (GO:0097060) and synapse part (GO:0045202)]. Furthermore, the "turquoise" module was also enriched for GO terms in the MF category associated with cellular transport, which included ion transport (GO:0006811) and calcium ion binding (GO:0005509; Figure 4B).

Both the "green" (604 $\mu$ atm $p \mathrm{CO}_{2}$ ) and the "purple" (2553 $\mu$ atm $p \mathrm{CO}_{2}$ ) modules included genes that were overrepresented under increased $\mathrm{pCO}_{2}$ (Figure 5). Interestingly, both of these modules exhibited significant $\mathrm{GO}$ enrichment in the CC category for the term mitochondrial part (GO:0044429; Figures 5A,B). The "purple" module included enrichment of GO terms related to hydrogen ion/proton transport [e.g., hydrogen ion transmembrane transporter (GO:1902600) and ATP synthesis coupled proton transport (GO:0015986)] across all GO categories, suggesting that these pathways were particularly enriched at 2553 $\mu$ atm $\mathrm{pCO}_{2}$ (Figure 5B). Lastly, the "purple" module was also enriched with GO terms in the BP category associated with cell death, which included apoptotic signaling pathway (GO:0097190) and regulation of cell death (GO:0010941).

\section{DISCUSSION}

\section{Contrasting Transcriptomic Responses to Temperature and $\mathrm{pCO}_{2}$}

Transcriptomic responses of $S$. siderea to thermal and acidification stress were highly divergent, with warming causing broad-scale disruption of genes associated with homeostasis and acidification causing overrepresentation of genes associated 


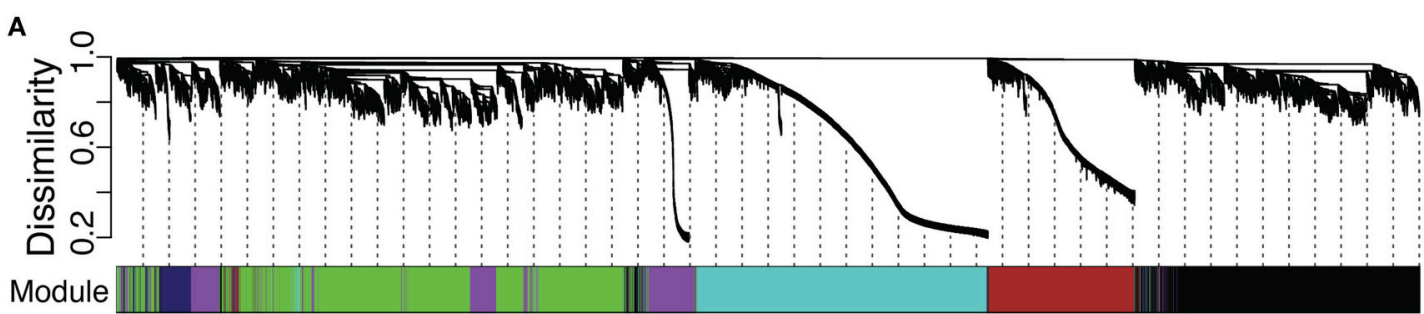

B

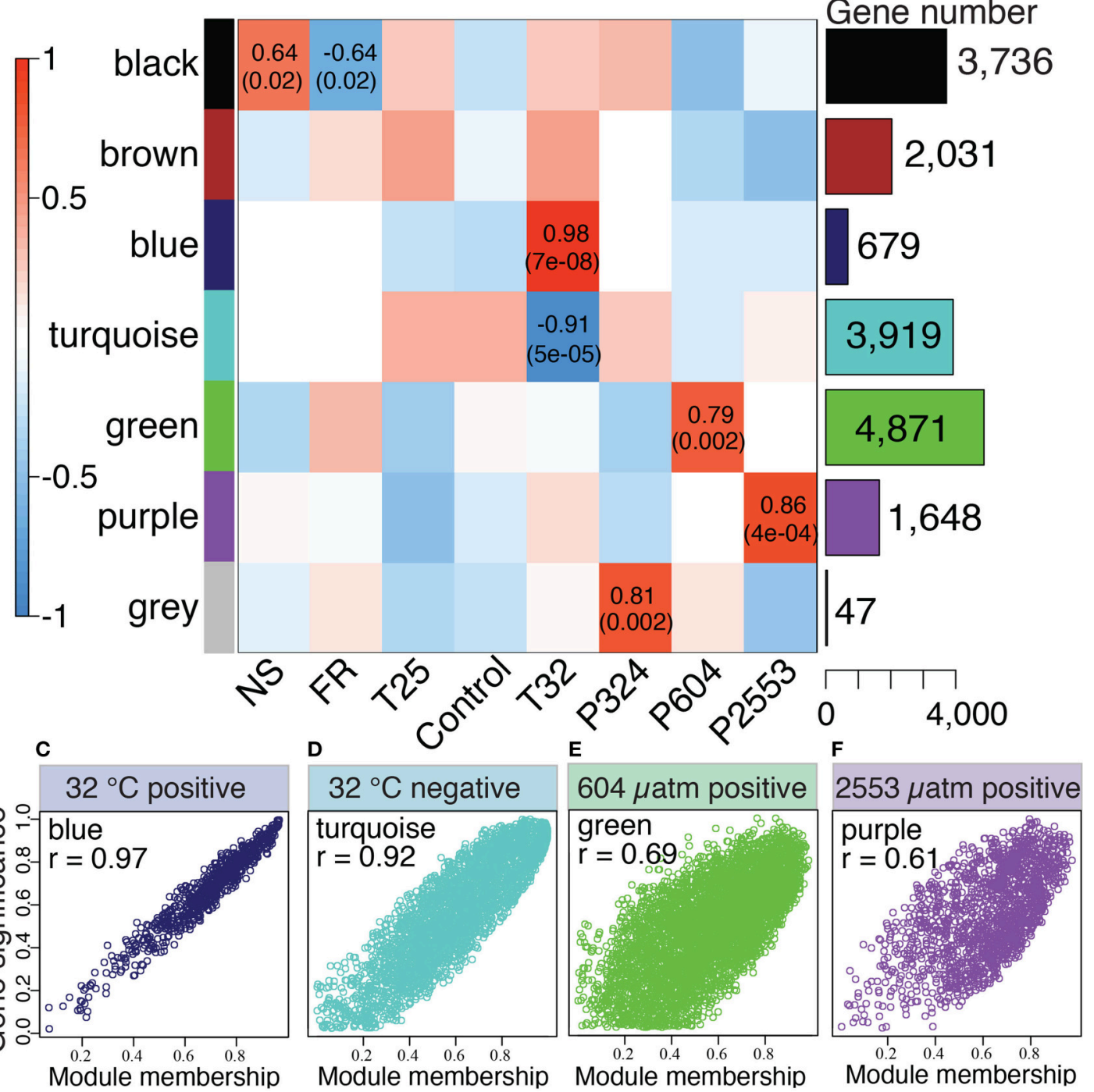

FIGURE 3 | Network analysis of Siderastrea siderea gene expression. (A) Dendrogram showing clustering of genes based on similarity of their expression patterns among all libraries, regardless of experimental treatment. The colored bar below the dendrogram denotes inferred co-expression modules. (B) Correlations between module eigengenes (rows) and presence-absence of a particular treatment (columns). The bar graph and numbers on the right indicate number of genes belonging to each module. The two numbers in the cells are Pearson's correlation coefficients and $p$-values of the correlation test (not listed for cells with $p>0.05$ ). (C-F) Scatterplots illustrating the relationship between a gene's module membership score ( $\mathrm{x}$-axis) and the gene's significance for the experimental treatment ( $\mathrm{y}$-axis). Higher correlations between these parameters indicate stronger associations of the "blue" (C), "turquoise" (D), "green" (E), and "purple" (F) modules with their associated treatments $\left(32^{\circ} \mathrm{C}, 32^{\circ} \mathrm{C}, 604 \mu \mathrm{atm}\right.$, and $2553 \mu \mathrm{atm}$, respectively).

with ion transport and respiration (Figures 4, 5). The divergent nature of these transcriptomic responses is consistent with that observed for terrestrial (Arabidopsis; Rizhsky et al., 2004) and other marine (Crassostrea virginica; Chapman et al., 2011) organisms exposed to multiple stressors. Notably, however, no modules were correlated with the low $\mathrm{pCO}_{2}$ or low temperature treatments (Figure 3B). This observation, combined with the reduced numbers of DEGs observed in these treatments (Figure 2A) suggests that low temperature and low $p \mathrm{CO}_{2}$ do not generate strong transcriptomic responses in S. siderea. 


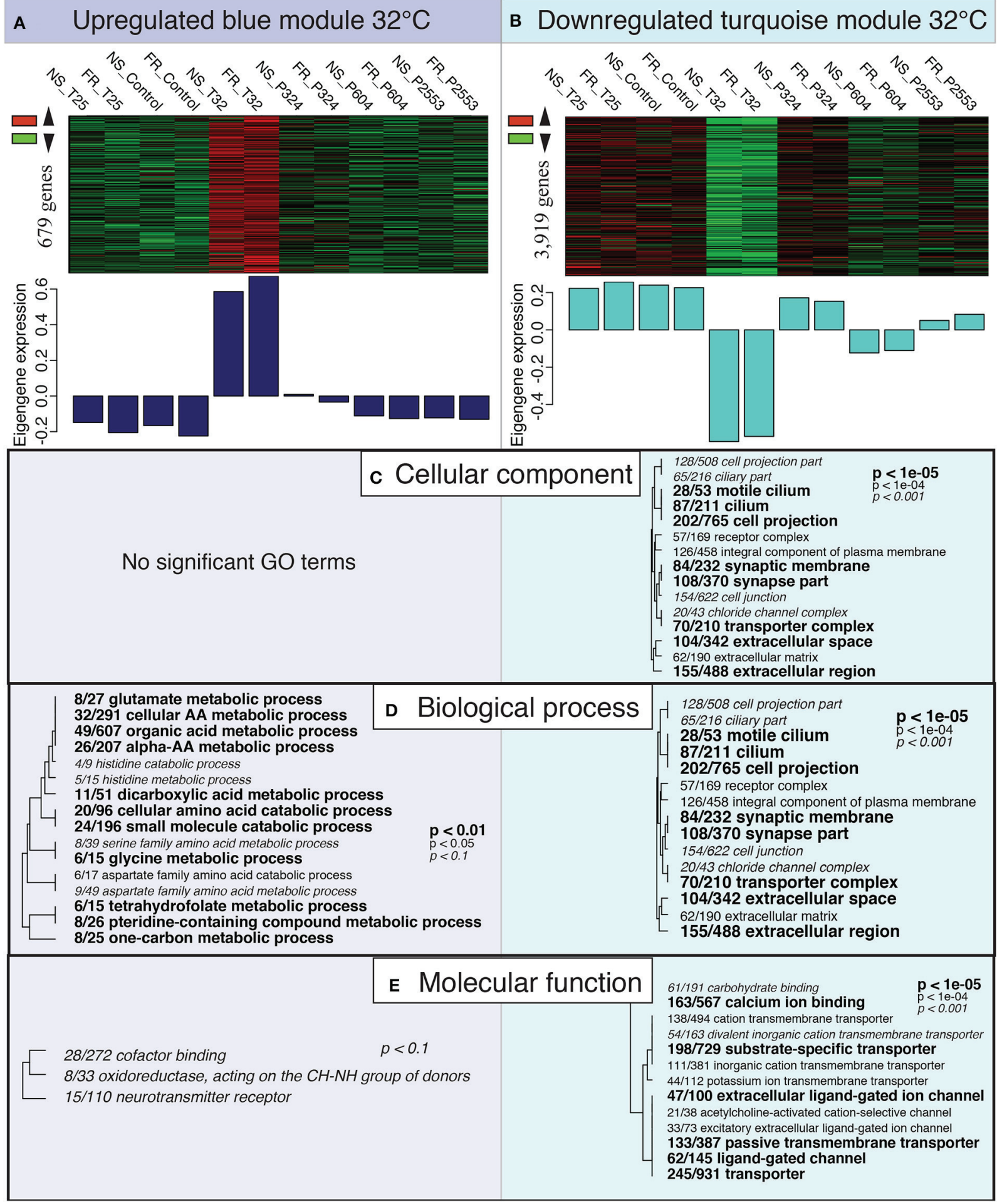

FIGURE 4 | Expression modules correlated with high temperature treatment. Heatmaps of all genes assigned to the "blue" (A) and "turquoise" (B) modules by individual RNAseq libraries and barplots showing the relative eigengene expression for that sample. Bars $>0$ indicate overall higher expression of genes in that module (i.e., $32^{\circ} \mathrm{C}$ samples for the "blue" module), while bars $<0$ indicate lower expression of genes in that module (i.e., $32^{\circ} \mathrm{C}$ samples for the "turquoise" module). (C-E) Gene Ontology (GO) categories significantly enriched for each expression module by "cellular component" (C), "biological process" (D) and "molecular function" (E) using Fisher's exact test. Dendrograms depict sharing of genes between categories (the categories with no branch length between them are subsets of each other), with the fraction corresponding to proportion of genes contained within the module relative to the total number of genes within the GO category. Text size and boldness indicate the significance (Fisher's exact test) of the term, as indicated by the inset key. 
A Upregulated green module $604 \mu \mathrm{atm}$ B Upregulated purple module $2553 \mu \mathrm{atm}$

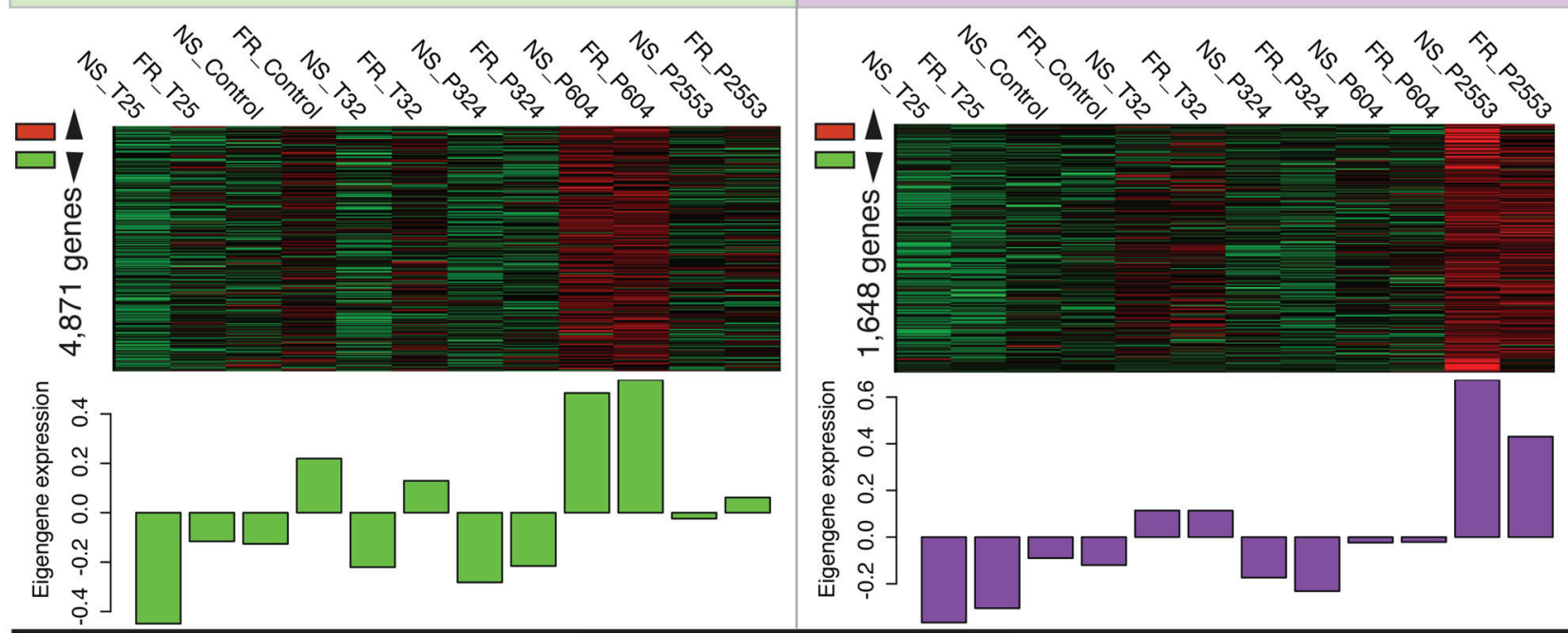

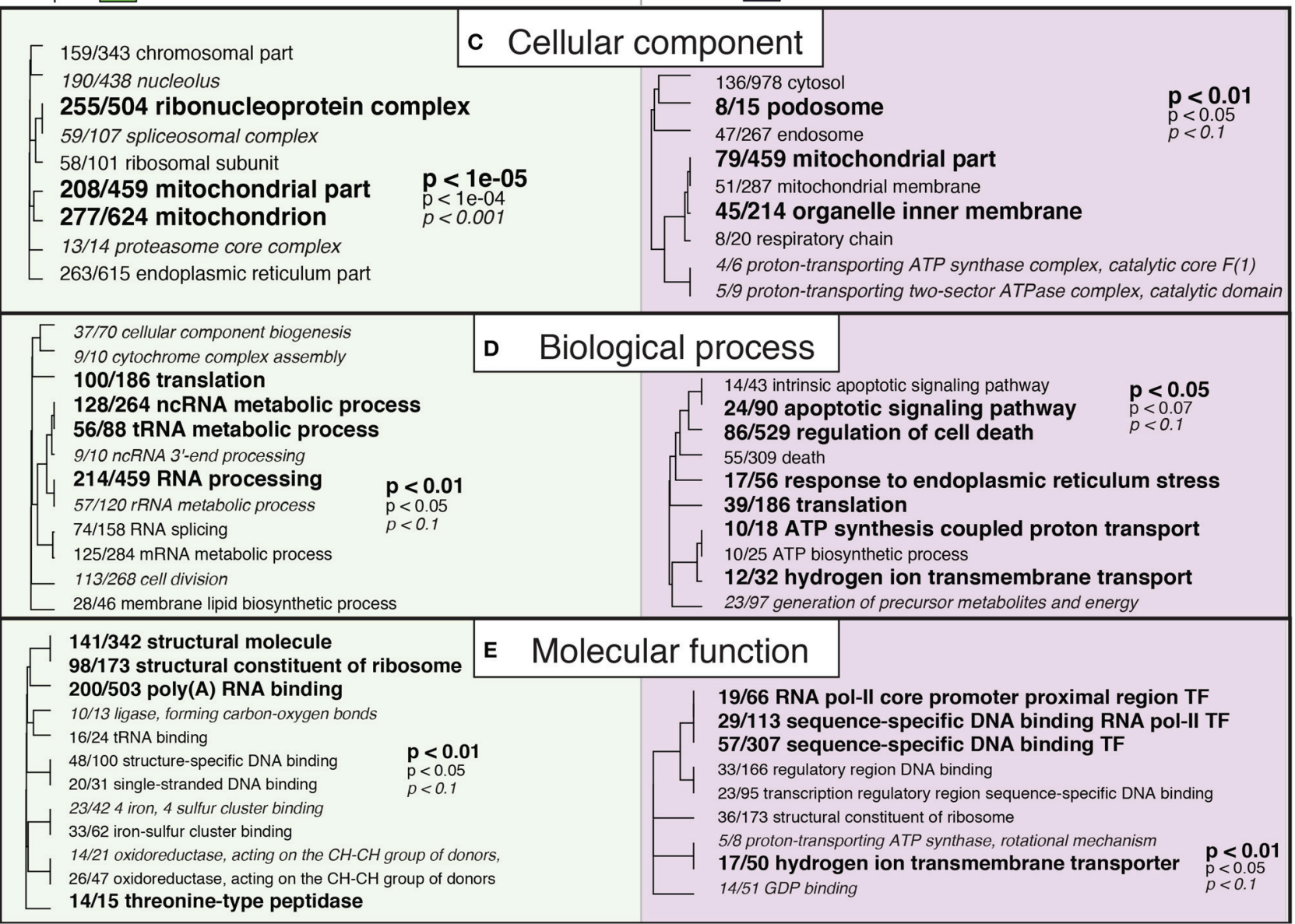

FIGURE 5 | Expression modules correlated with high $p \mathrm{CO}_{2}$ treatment. Heatmaps of all genes assigned to the "green" (A) and "purple" (B) modules by individual RNAseq libraries and barplots showing the relative eigengene expression for that sample. Bars $>0$ indicate overall higher expression of the genes in that module. (C-E) Gene ontology (GO) categories significantly enriched for each expression module by "cellular component" (C), "biological process" (D) and "molecular function" (E) using Fisher's exact test. Dendrograms depict sharing of genes between categories (the categories with no branch length between them are subsets of each other), the fraction corresponds to genes contained within the module relative to the total number of genes within the GO category. Text size and boldness indicate the significance (Fisher's exact test) of the term, as indicated by the inset key. 
Calcification rates for corals grown under pre-industrial (324 $\mu \mathrm{atm})$ and extreme-high $(2553 \mu \mathrm{atm}) \mathrm{pCO}_{2}$ were statistically indistinguishable; Figure 1B). Conversely, the transcriptome at $p \mathrm{CO}_{2}$ of $2553 \mu \mathrm{atm}$ exhibited many more overrepresented genes than at $324 \mu \mathrm{atm}$. This transcriptomic enrichment of genes linked to proton regulation at $2553 \mu \mathrm{atm} p \mathrm{CO}_{2}$ may play a role in the capacity of $S$. siderea to acclimate to extreme-high $p \mathrm{CO}_{2}$, enabling these corals to continue calcifying (albeit at a slower rate) throughout the 95-day experiment, even at near undersaturated conditions. However, additional physiological measurements are needed to unambiguously define the relationship between the observed transcriptomic responses and the role that $\mathrm{pH}$ regulation at the site of calcification plays in defining a coral's response to ocean acidification. Furthermore, the observed metabolic restructuring of $S$. siderea's transcriptome under extreme-high $p \mathrm{CO}_{2}$ also involved increased expression of respiration-linked genes (Figure 5C), which is consistent with the hypothesis that this acclimation is energetically costly. However, a strict test of this hypothesis would require direct measurement of respiration rates and energy reserves, neither of which were quantified in the present study.

Acclimation costs and/or tradeoffs have been previously documented in corals. For example, Jones and Berkelmans (2010) found that corals hosting more thermally tolerant Symbiodinium (clade D), potentially for thermal acclimation, exhibited a nearly $38 \%$ reduction in calcification rates. Although energetic costs appear to be manifest as impaired calcification rates in the previous example (Jones and Berkelmans, 2010), this was not observed in the present study on S. siderea. Corals in the low $\mathrm{pCO}_{2}$ treatments exhibited little transcriptomic change, but calcified at the same rate as the extreme-high $p \mathrm{CO}_{2}$ corals, which exhibited substantial transcriptomic modifications. However, it is possible that the increased metabolic costs associated with this broadscale upregulation in the extreme-high $\mathrm{pCO}_{2}$ treatments was not captured by the net calcification measurements (Lang et al., 2009). Indeed, previous work has demonstrated that tissue growth may be more responsive to environmental stress than skeletal growth (Anthony et al., 2002), which highlights the importance of measuring both tissue and skeletal growth in future coral stress experiments.

\section{Metabolic Modifications and Homeostatic Disturbance under High Temperature}

Two modules were associated with the transcriptomic response to extreme temperature $\left(32^{\circ} \mathrm{C}\right)$ after 95 days ("blue" and "turquoise", Figure 3). Gene Ontology enrichment analysis of the overrepresented extreme temperature module ("blue") suggests metabolic modification-specifically, increased catabolism (Figure 4D). This is consistent with the assertion that metabolic depression is an adaptive strategy for managing short-term stress (Portner and Farrell, 2008). However, under the long-term stress implemented in this study, the most overrepresented GO term in the "blue" module was cellular amino acid catabolic process (Figure 3D, GO:0009063). This transcriptomic response suggests that the corals' response to long-term heat stress may promote protein breakdown. In healthy corals, symbiont-derived photosynthetic products have been shown to provide up to $100 \%$ of their daily metabolic requirements. In bleached corals, however, these inputs of organic carbon decrease and corals must rely more heavily on energy reserves and/or heterotrophy to survive (Grottoli et al., 2006). In the present study, S. siderea specimens at $32^{\circ} \mathrm{C}$ exhibited varying degrees of bleaching after 95 days. It is therefore possible that the corals' energy reserves were diminished or depleted under these conditions-although these physiological parameters (e.g., lipid, protein, carbohydrate) were not quantified in the present study.

In the highly underrepresented module for $32^{\circ} \mathrm{C}$ ("turquoise"), GO enrichment analysis suggested downregulation of what are generally considered key biological processes, including cilium (GO:0005929), synaptic membrane (GO:0097060), synapse part (GO:004520), ion transport (GO:0006811), and calcium ion binding (GO:0005509; Figures 4C-E). Coral cilia have been compared to the external neuromasts in the lateral lines of fish (Vermeij et al., 2010), which are used to detect environmental stimuli and are also known to play important roles in muco-ciliary processes that can be disrupted during bleaching (Brown and Bythell, 2005). In addition, reductions in calcium ion binding may indicate the interruption of cell-signaling pathways (Kaniewska et al., 2012). Collectively, these disruptions suggest a restriction of the coral's ability to respond to their environment under thermal stress. These reductions in ion transport and calcium ion binding may also reflect disruption of calcification, as the downregulation of these categories has been consistently associated with the coral transcriptomic response to increased $\mathrm{pCO}_{2}$ (Kaniewska et al., 2012), increased UV radiation (Aranda et al., 2011), and bleaching (DeSalvo et al., 2008). Although one cannot be certain what these GO categories represent in terms of coral physiology, the observed widespread underrepresentation of transcripts has been previously observed in corals (Meyer et al., 2011; Vidal-Dupiol et al., 2014), oysters (Zhao et al., 2012), and even yeast (Gasch et al., 2000) exposed to environmental stress, suggesting that gene downregulation may be a conserved transcriptomic response to severe environmental stress. The underrepresentation of genes (this study) and correspondingly reduced rates of calcification (Castillo et al., 2014) observed for $S$. siderea cultured for 95 days at $32^{\circ} \mathrm{C}$ (Figure 1) suggest that this temperature stress exceeds this species' threshold for acclimation.

\section{Overrepresentation of Metabolism and Proton-Pumping under Increased $p \mathrm{CO}_{2}$}

Two modules were significantly associated with the corals' transcriptomic response to $p \mathrm{CO}_{2}$ after 95 days: the "green" module, which included overrepresented genes (4871) at 604 $\mu$ atm $p \mathrm{CO}_{2}$, and the "purple" module, which showed strong overrepresentation of genes (1648 genes) at $2553 \mu \mathrm{atm} p \mathrm{CO}_{2}$ (Figures 3, 5). Both modules exhibited GO enrichment for mitochondrial part (GO:0044429), suggesting that oxidative metabolism in $S$. siderea may increase under high and extremehigh $\mathrm{pCO}_{2}$ (Figures 5C-E), which is consistent with the hypothesis that the maintenance of calcification under these 
conditions comes with increased energetic demands. This finding contrasts the results of other transcriptomic studies investigating the effects of acidification on corals (Kaniewska et al., 2012; Moya et al., 2012), which observed a reduction in the expression of genes involved in respiration under increased $p \mathrm{CO}_{2}$. Results of these studies may differ from the results of the present study on S. siderea because corals in the present experiment were exposed to environmental stress for a much longer period of time (95 days), at least three times longer than any previous study investigating coral transcriptomic responses to increased $p \mathrm{CO}_{2}$ and temperature, thereby providing more time for the corals to acclimate. However, these differences may also reflect interspecific variation, since $S$. siderea is known to be highly resilient and better able to cope with chronic environmental stress (Colella et al., 2012; Castillo et al., 2014), and/or different life history stages.

The highly overrepresented module at $2553 \mu$ atm $p \mathrm{CO}_{2}$ ("purple") included GO enrichment for hydrogen ion transmembrane transporter (GO:1902600) and ATP synthesis coupled proton transport (GO:0015986; Figure 5), suggesting that upregulation of hydrogen ion $\left(\mathrm{H}^{+} /\right.$proton) transport is a major component of the corals' transcriptomic response to extremehigh $p \mathrm{CO}_{2}$. Proton-transport out of the coral calcifying fluid (thereby increasing calcifying fluid saturation state with respect to aragonite) has previously been proposed as a mechanism for coral calcification (Cohen and McConnaughey, 2003), with microelectrode (Ries, 2011), boron isotope (McCulloch et al., 2012), antibody immunolabeling (Barott et al., 2015), and $\mathrm{pH}$ sensitive dye studies (Venn et al., 2013) demonstrating that corals are able to calcify under normal and elevated $p \mathrm{CO}_{2}$ by elevating $\mathrm{pH}$ of their calcifying fluid relative to their surrounding seawater. $\mathrm{Ca}^{2+}$ plasma membrane ATPase upregulation was observed in P. damicornis, although this result was only observed at two (856 and $2181 \mu \mathrm{atm})$ of the three $(3880 \mu \mathrm{atm})$ high $-p \mathrm{CO}_{2}$ treatments (Vidal-Dupiol et al., 2013). Kaniewska et al. (2012) describe enrichment of $\mathrm{H}^{+}$-exchange pathways in corals exposed to elevated $p \mathrm{CO}_{2}$. However, GO enrichment does not necessarily indicate expression direction and further inspection of V-type ATPase actually suggested downregulation of $\mathrm{H}^{+}$-exchange under increased $p \mathrm{CO}_{2}$ in A. millepora. Furthermore, Kaniewska et al. (2012) observed no differences in A. millepora calcification across $p \mathrm{CO}_{2}$ treatments, raising the possibility that this species mitigates effects of ocean acidification by regulating $\mathrm{pH}$ at the site of calcification. We also report the overrepresentation and upregulation of $\mathrm{H}^{+}$-transport genes under elevated $p \mathrm{CO}_{2}$, even though reductions in calcification rate were observed under the most extreme $\mathrm{pCO}_{2}$ treatment (Castillo et al., 2014).

These species-level differences in transcriptomic and calcification responses to acidification are consistent with the assertion that marine calcifiers that have stronger control over the $\mathrm{pH}$ of their calcifying fluid are more resilient to the effects of acidification, and that this ability varies amongst species (Ries, 2011). Furthermore, this potential to acclimate to ocean acidification via increased expression of genes linked to proton transport may be energetically costly (Cohen and McConnaughey, 2003). Although these costs have not yet been substantiated with physiological measurements, their existence is supported by the gene expression data showing increased oxidative metabolism via the respiration pathway under conditions of elevated $p \mathrm{CO}_{2}$ (Figure 5).

\section{Implications for Coral Acclimation to Global Change}

Under ocean acidification scenarios predicted for the next several centuries, observed expression patterns (i.e., general upregulation) were suggestive of acclimation, demonstrating that the S. siderea populations investigated in this study are resilient to substantial acidification stress over the time scale that they were investigated. However, under the extreme temperatures tested here, expression patterns (i.e., general downregulation) corroborate previous observations of substantially reduced calcification rates, which collectively suggest physiological shutdown of the coral under such extreme temperature conditions. These results are consistent with prior physiologicalbased studies showing that ocean warming poses a greater threat to the coral S. siderea than ocean acidification, at least at levels predicted for the next several centuries. However, it is important to note that although this experiment was conducted over a relatively long duration (95 days), it is possible that this species would continue to acclimate to these stressors beyond the 95-day window that they were evaluated, and to evolve via natural selection over much longer timescales. Furthermore, because $\mathrm{CO}_{2}$-induced warming and acidification may occur in tandem over the foreseeable future, it is critical that future studies also assess the combined and interactive effects of these stressors on the transcriptomic profile and physiology of $S$. siderea and other scleractinian corals. Lastly, despite apparent acclimation of the corals to acidification via overrepresentation of calcification-linked genes, these transcriptomic responses appear to come with energetic costs that may ultimately limit corals' resilience to acidification. Future investigations of corals' transcriptomic responses to acidification and thermal stress should seek to constrain these potential linkages between differential gene expression and acclimation by coupling transcriptomic observations with detailed measurements of key physiological parameters beyond calcification rate, such as lipid and tissue content, rates of photosynthesis and respiration, and protein degradation.

\section{FUNDING}

Coral $p \mathrm{CO}_{2}$-temperature experiments were supported by NOAA award NA13OAR4310186 (to JR and KC) and NSF award OCE1357665 (to JR), sequencing-related activities were supported by AM/KC/JR's start-ups and NSF award 1357665 (to JR), and salary/travel for SD was supported by AM/KC/JR's start-ups, NSF awards OCE-1437371, OCE-1459706 (to JR), and NSF OCE1459522 (to KC).

\section{AUTHOR CONTRIBUTIONS}

$\mathrm{KC}$ and JR designed the study. AM completed all molecular preparations for sequencing. SD analyzed data with contributions from AM. SD wrote the paper with contributions from AM, JR, and KC. 


\section{ACKNOWLEDGMENTS}

We thank Garbutt Marine for help in the field and Belize Fisheries Department for permit authorization. B. Elder, E. Chow, K. Patel, R. Yost, and D. Shroff helped maintain the experimental tanks and I. Westfield analyzed carbonate chemistry of the experimental treatments. N. Cohen and K. Delong performed coral tissue extractions and preservations, and $\mathrm{H}$. Masters performed RNA extractions. We are grateful to M. Matz, D. Barshis, M. Love, and S. Vollmer for guidance on transcriptome assembly and gene expression analyses.

\section{SUPPLEMENTARY MATERIAL}

The Supplementary Material for this article can be found online at: http://journal.frontiersin.org/article/10.3389/fmars. 2016.00112

\section{REFERENCES}

Anthony, K. R. N., Connolly, S. R., and Willis, B. L. (2002). Comparative analysis of energy allocation to tissue and skeletal growth in corals. Limnol. Oceanogr. 47, 1417-1429. doi: 10.4319/lo.2002.47.5.1417

Aranda, M., Banaszak, A. T., Bayer, T., Luyten, J. R., Medina, M., and Voolstra, C. R. (2011). Differential sensitivity of coral larvae to natural levels of ultraviolet radiation during the onset of larval competence. Mol. Ecol. 20, 2955-2972. doi: 10.1111/j.1365-294X.2011.05153.x

Barott, K. L., Perez, S. O., Linsmayer, L. B., and Tresguerres, M. (2015). Differential localization of ion transporters suggests distinct cellular mechanisms for calcification and photosynthesis between two coral species. Am. J. Physiol. Regul. Integr. Comp. Physiol. 309, R235-R246. doi: 10.1152/ajpregu.00052.2015

Barshis, D. J., Ladner, J. T., Oliver, T. A., Seneca, F. O., Traylor-Knowles, N., and Palumbi, S. R. (2013). Genomic basis for coral resilience to climate change. Proc. Natl. Acad. Sci. U.S.A. 110, 1387-1392. doi: 10.1073/pnas.1210224110

Bayer, T., Aranda, M., Sunagawa, S., Yum, L. K., DeSalvo, M. K., Lindquist, E., et al. (2012). Symbiodinium transcriptomes: genome insights into the dinoflagellate symbionts of reef-building corals. PLoS ONE 7:e35269. doi: 10.1371/journal.pone.0035269

Benjamini, Y., and Hochberg, Y. (1995). Controlling the false discovery rate: a practical and powerful approach to multiple testing. J. R. Stat. Soc. B 57, 289-300.

Bindoff, N. L., Willebrand, J., Artale, V., Cazenave, A., Gregory, J., Gulev, S., et al. (2007). "Observations: oceanic climate change and sea level," in Climate Change 2007: The Physical Science Basis. Contribution of Working Group I to the Fourth Assessment Report of the Intergovernmental Panel on Climate Change, eds S. Solomon, D. Qin, M. Manning, Z. Chen, M. Marquis, K. B. Averyt, M. Tignor and H. L. Miller (New York, NY; Cambridge, UK: Cambridge University Press), 385-432.

Brown, B. E., and Bythell, J. C. (2005). Perspectives on mucus secretion in reef corals. Mar. Ecol. Prog. Ser. 296, 291-309. doi: 10.3354/meps296291

Castillo, K. D., and Helmuth, B. S. T. (2005). Influence of thermal history on the response of Montastraea annularis to short-term temperature exposure. Mar. Biol. 148, 261-270. doi: 10.1007/s00227-005-0046-x

Castillo, K. D., and Lima, F. P. (2010). Comparison of in situ and satellite-derived (MODIS-Aqua/Terra) methods for assessing temperatures on coral reefs. Limnol. Oceanogr. Methods 8, 107-117. doi: 10.4319/lom.2010. 8.0107

Castillo, K. D., Ries, J. B., Bruno, J. F., and Westfield, I. T. (2014). The reef-building coral Siderastrea siderea exhibits parabolic responses to ocean acidification and warming. Proc. R. Soc. B 281:20141856. doi: 10.1098/rspb. 2014.1856

Castillo, K. D., Ries, J. B., Weiss, J. M., and Lima, F. P. (2012). Decline of forereef corals in response to recent warming linked to history of thermal exposure. Nat. Clim. Chang. 2, 756-760. doi: 10.1038/nclimate1577
Supplementary Figure 1 | Sample profile of photosynthetically active radiation (PAR) within the temperature and $p \mathrm{CO}_{2}$ treatment tanks over a 24-h interval during the 95-day experiment. Light profile was designed to replicate the light cycle at 3 to $5 \mathrm{~m}$ depth where Siderastrea siderea coral colonies were collected.

Supplementary Figure 2 | Transcriptome contiguity based on the Siderastrea siderea transcriptome blastx hits to the reference protein database, with visualized distribution of reference coverages based on the longest matching contig. Forty-seven percent of the S. siderea transcriptome has protein coverage $>0.75$.

Supplementary Figure 3 | Principal coordinate analysis (PCoA) of all r-log transformed isogroups clustered by experimental treatment demonstrating significantly different transcriptomic responses of corals across different experimental treatments, regardless of reef zone origin ("NS" = nearshore and "FR" = forereef; Adonis ptreatment $<0.001$, Adonis psite $=\mathbf{0 . 0 5 5 )}$. Symbol colors represent treatment conditions: black $=$ control: $\left(477 \mu \mathrm{atm}, 28^{\circ} \mathrm{C}\right)$, green $=$ low $\mathrm{pCO}_{2}\left(324 \mu \mathrm{atm}, 28^{\circ} \mathrm{C}\right)$, brown $=$ high $p \mathrm{CO}_{2}$ $\left(604 \mu \mathrm{atm}, 28^{\circ} \mathrm{C}\right)$, orange $=$ extreme-high $\mathrm{pCO}_{2}\left(2553 \mu \mathrm{atm}, 28^{\circ} \mathrm{C}\right)$, blue $=$ low temperature $\left(515 \mu \mathrm{atm}, 25^{\circ} \mathrm{C}\right)$, and red $=$ high temperature $\left(472 \mu \mathrm{atm}, 32^{\circ} \mathrm{C}\right)$.

Chan, N. C. S., and Connolly, S. R. (2013). Sensitivity of coral calcification to ocean acidification: a meta-analysis. Glob. Chang. Biol. 19, 282-290. doi: $10.1111 /$ gcb. 12011

Chapman, R. W., Mancia, A., Beal, M., Veloso, A., Rathburn, C., Blair, A., et al. (2011). The transcriptomic responses of the eastern oyster, Crassostrea virginica, to environmental conditions. Mol. Ecol. 20, 1431-1449. doi: 10.1111/j.1365-294X.2011.05018.X

Chua, C. M., Leggat, W., Moya, A., and Baird, A. H. (2013). Temperature affects the early life history stages of corals more than near future ocean acidification. Mar. Ecol. Prog. Ser. 475, 85-92. doi: 10.3354/meps 10077

Cohen, A. L., and McConnaughey, T. A. (2003). Geochemical perspectives on coral mineralization. Biomineralization 54, 151-187. doi: 10.2113/0540151

Colella, M. A., Ruzicka, R. R., Kidney, J. A., Morrison, J. M., and Brinkhuis, V. B. (2012). Cold-water event of January 2010 results in catastrophic benthic mortality on patch reefs in the Florida Keys. Coral Reefs 31, 621-632. doi: $10.1007 /$ s00338-012-0880-5

Consortium, T. U. (2015). UniProt: a hub for protein information. Nucleic Acids Res. 43, D204-D212. doi: 10.1093/nar/gku989

Cooper, T. F., De'Ath, G., Fabricius, K. E., and Lough, J. M. (2008). Declining coral calcification in massive Porites in two nearshore regions of the northern Great Barrier Reef. Glob. Chang. Biol. 14, 529-538. doi: 10.1111/j.13652486.2007.01520.x

Daniels, C. A., Baumgarten, S., Yum, L. K., Michell, C. T., Bayer, T., Arif, C., et al. (2015). Metatranscriptome analysis of the reef-building coral Orbicella faveolata indicates holobiont response to coral disease. Front. Mar. Sci. 2:62. doi: $10.3389 /$ fmars.2015.00062

De'Ath, G., Lough, J. M., and Fabricius, K. E. (2009). Declining coral calcification on the great barrier reef. Science 323, 116-119. doi: 10.1126/science.1165283

DeSalvo, M. K., Voolstra, C. R., Sunagawa, S., Schwarz, J. A., Stillman, J. H., Coffroth, M. A., et al. (2008). Differential gene expression during thermal stress and bleaching in the Caribbean coral Montastraea faveolata. Mol. Ecol. 17 3952-3971. doi: 10.1111/j.1365-294X.2008.03879.x

Dixon, G. B., Davies, S. W., Aglyamova, G. A., Meyer, E., Bay, L. K., and Matz, M. V. (2015). Genomic determinants of coral heat tolerance across latitudes. Science 348, 1460-1462. doi: 10.1126/science.1261224

Doney, S. C., Fabry, V. J., Feely, R. A., and Kleypas, J. A. (2009). Ocean acidification: the other $\mathrm{CO}_{2}$ problem. Ann. Rev. Mar. Sci. 1, 169-192. doi: 10.1146/annurev.marine.010908.163834

Doney, S. C., Ruckelshaus, M., Duffy, J. E., Barry, J. P., Chan, F., English, C. A., et al. (2012). Climate change impacts on marine ecosystems. Ann. Rev. Mar. Sci. 4, 11-37. doi: 10.1146/annurev-marine-041911111611

Gasch, A. P., Spellman, P. T., Kao, C. M., Carmel-Harel, O., Eisen, M. B., Storz, G., et al. (2000). Genomic expression programs in the response of yeast cells to environmental changes. Mol. Biol. Cell 11, 4241-4257. doi: $10.1091 / \mathrm{mbc} .11 .12 .4241$ 
Grabherr, M. G., Haas, B. J., Yassour, M., Levin, J. Z., Thompson, D. A., Amit, I., et al. (2011). Full-length transcriptome assembly from RNA-Seq data without a reference genome. Nat. Biotechnol. 29, 644-652. doi: 10.1038/nbt.1883

Grottoli, A. G., Rodrigues, L. J., and Palardy, J. E. (2006). Heterotrophic plasticity and resilience in bleached corals. Nature 440, 1186-1189. doi: 10.1038 /nature 04565

Hoegh-Guldberg, O., Mumby, P. J., Hooten, A. J., Steneck, R. S., Greenfield, P., Gomez, E., et al. (2007). Coral reefs under rapid climate change and ocean acidification. Science 318, 1737-1742. doi: 10.1126/science.1152509

Jones, A., and Berkelmans, R. (2010). Potential costs of acclimatization to a warmer climate: growth of a reef coral with heat tolerant vs. sensitive symbiont types. PLoS ONE 5:e10437. doi: 10.1371/journal.pone.0010437

Kaniewska, P., Campbell, P. R., Kline, D. I., Rodriguez-Lanetty, M., Miller, D. J., Dove, S., et al. (2012). Major cellular and physiological impacts of ocean acidification on a reef building coral. PLoS ONE 7:e34659. doi: 10.1371/journal.pone.0034659

Kendziorski, C. M., Zhang, Y., Lan, H., and Attie, A. D. (2003). The efficiency of pooling mRNA in microarray experiments. Biostatistics 4, 465-477. doi: 10.1093/biostatistics/4.3.465

Kenkel, C. D., Goodbody-Gringley, G., Caillaud, D., Davies, S. W., Bartels, E., and Matz, M. V. (2013a). Evidence for a host role in thermotolerance divergence between populations of the mustard hill coral (Porites astreoides) from different reef environments. Mol. Ecol. 22, 4335-4348. doi: 10.1111/mec.12391

Kenkel, C. D., Meyer, E., and Matz, M. V. (2013b). Gene expression under chronic heat stress in populations of the mustard hill coral (Porites astreoides) from different thermal environments. Mol. Ecol. 22, 4322-4334. doi: $10.1111 /$ mec. 12390

Kitahara, M. V., Cairns, S. D., Stolarski, J., Blair, D., and Miller, D. J. (2010). A comprehensive phylogenetic analysis of the scleractinia (Cnidaria, Anthozoa) based on mitochondrial CO1 sequence data. PLOS ONE 5:e11490. doi: 10.1371/journal.pone.0011490

Kleypas, J. A., and Yates, K. K. (2009). Coral Reefs and Ocean Acidification. Oceanography 22, 108-117. doi: 10.5670/oceanog.2009.101

Ladner, J. T., Barshis, D. J., and Palumbi, S. R. (2012). Protein evolution in two co-occurring types of Symbiodinium: an exploration into the genetic basis of thermal tolerance in Symbiodiniumclade D. BMC Evol. Biol. 12:217. doi: 10.1186/1471-2148-12-217

Ladner, J. T., and Palumbi, S. R. (2012). Extensive sympatry, cryptic diversity and introgression throughout the geographic distribution of two coral species complexes. Mol. Ecol. 21, 2224-2238. doi: 10.1111/j.1365-294X.2012.05528.x

Lang, G. I., Murray, A. W., and Botstein, D. (2009). The cost of gene expression underlies a fitness trade-off in yeast. Proc. Natl. Acad. Sci. U.S.A. 106, 5755-5760. doi: 10.1073/pnas.0901620106

Langdon, C., and Atkinson, M. J. (2005). Effect of elevated $\mathrm{pCO}_{2}$ on photosynthesis and calcification of corals and interactions with seasonal change in temperature/irradiance and nutrient enrichment. J. Geophys. Res. 110, C09S07. doi: 10.1029/2004JC002576

Langfelder, P., and Horvath, S. (2008). WGCNA: an R package for weighted correlation network analysis. BMC Bioinformatics 9:559. doi: 10.1186/14712105-9-559

Langmead, B., and Salzberg, S. L. (2012). Fast gapped-read alignment with Bowtie 2. Nat. Methods 9, 357-359. doi: 10.1038/nmeth.1923

Lehnert, E. M., Burriesci, M. S., and Pringle, J. R. (2012). Developing the anemone Aiptasia as a tractable model for cnidarian-dinoflagellate symbiosis: the transcriptome of aposymbiotic A. pallida. BMC Genomics 13:271. doi: 10.1186/1471-2164-13-271

Lirman, D., and Fong, P. (2007). Is proximity to land-based sources of coral stressors an appropriate measure of risk to coral reefs? An example from the Florida Reef Tract. Mar. Pollut. Bull. 54, 779-791. doi: 10.1016/j.marpolbul.2006.12.014

Love, M. I., Huber, W., and Anders, S. (2014). Moderated estimation of fold change and dispersion for RNA-seq data with DESeq2. Genome Biol. 15, 550. doi: 10.1186/s13059-014-0550-8

McCulloch, M., Falter, J., Trotter, J., and Montagna, P. (2012). Coral resilience to ocean acidification and global warming through $\mathrm{pH}$ up-regulation. Nat. Clim. Chang. 2, 623-633. doi: 10.1038/nclimate1473

Meyer, E., Aglyamova, G. V., and Matz, M. V. (2011). Profiling gene expression responses of coral larvae (Acropora millepora) to elevated temperature and settlement inducers using a novel RNA-Seq procedure. Mol. Ecol. 20, 3599-3616. doi: 10.1111/j.1365-294x.2011.05205.x

Moberg, F., and Folke, C. (1999). Ecological goods and services of coral reef ecosystems. Ecol. Econ. 29, 215-233. doi: 10.1016/S0921-8009(99) 00009-9

Moya, A., Huisman, L., Ball, E. E., Hayward, D. C., Grasso, L. C., Chua, C. M., et al. (2012). Whole transcriptome analysis of the coral Acropora millepora reveals complex responses to $\mathrm{CO}_{(2)}$-driven acidification during the initiation of calcification. Mol. Ecol. 21, 2440-2454. doi: 10.1111/j.1365-294X.2012. 05554.x

Moya, A., Huisman, L., Foret, S., Gattuso, J. P., Hayward, D. C., Ball, E. E., et al. (2015). Rapid acclimation of juvenile corals to $\mathrm{CO}_{2}$-mediated acidification by upregulation of heat shock protein and Bcl-2 genes. Mol. Ecol. 24, 438-452. doi: $10.1111 /$ mec. 13021

Oksanen, J. F., Blanchet, G., Kindt, R., Legendre, P., Minchin, P. R., O’Hara, R. B., et al. (2013). vegan: Community Ecology Package. R package version 2.0-7.

Pandolfi, J. M. (2015). Incorporating uncertainty in predicting the future response of coral reefs to climate change. Annu. Rev. Ecol. Evol. Syst. 46, 281-303. doi: 10.1146/annurev-ecolsys-120213-091811

Parra, G., Bradnam, K., and Korf, I. (2007). CEGMA: a pipeline to accurately annotate core genes in eukaryotic genomes. Bioinformatics 23, 1061-1067. doi: 10.1093/bioinformatics/btm071

Portner, H. O., and Farrell, A. P. (2008). ECOLOGY physiology and climate change. Science 322, 690-692. doi: 10.1126/science.1163156

Putnam, N. H., Srivastava, M., Hellsten, U., Dirks, B., Chapman, J., Salamov, A., et al. (2007). Sea anemone genome reveals ancestral eumetazoan gene repertoire and genomic organization. Science 317, 86-94. doi: $10.1126 /$ science. 1139158

R Development Core Team (2015). R: A Language and Environment for Statistical Computing. Vienna: R Foundation for Statistical Computing.

Ries, J. B. (2011). A physicochemical framework for interpreting the biological calcification response to $\mathrm{CO}_{2}$-induced ocean acidification. Geochim. Cosmochim. Acta 75, 4053-4064. doi: 10.1016/j.gca.2011. 04.025

Ries, J. B., Cohen, A. L., and McCorkle, D. C. (2009). Marine calcifiers exhibit mixed responses to $\mathrm{CO}_{2}$-induced ocean acidification. Geology 37, 1131-1134. doi: 10.1130/G30210A.1

Rizhsky, L., Liang, H. J., Shuman, J., Shulaev, V., Davletova, S., and Mittler, R. (2004). When Defense pathways collide. The response of Arabidopsis to a combination of drought and heat stress. Plant Physiol. 134, 1683-1696. doi: 10.1104/pp.103.033431

Rose, N. H., Seneca, F. O., and Palumbi, S. R. (2016). Gene networks in the wild: identifying transcriptional modules that mediate coral resistance to experimental heat stress. Genome Biol. Evol. 8, 243-252. doi: 10.1093/gbe/ evv258

Shinzato, C., Shoguchi, E., Kawashima, T., Hamada, M., Hisata, K., Tanaka, M., et al. (2011). Using the Acropora digitifera genome to understand coral responses to environmental change. Nature 476, 320-323. doi: 10.1038 /nature 10249

Shoguchi, E., Shinzato, C., Kawashima, T., Gyoja, F., Mungpakdee, S., Koyanagi, R., et al. (2013). Draft assembly of the Symbiodinium minutum nuclear genome reveals dinoflagellate gene structure. Curr. Biol. 23, 1399-1408. doi: 10.1016/j.cub.2013.05.062

van Hooidonk, R., Maynard, J. A., and Planes, S. (2013). Temporary refugia for coral reefs in a warming world. Nat. Clim. Chang. 3, 508-511. doi: $10.1038 /$ nclimate 1829

Venn, A. A., Tambutte, E., Holcomb, M., Laurent, J., Allemand, D., and Tambutte, S. (2013). Impact of seawater acidification on $\mathrm{pH}$ at the tissue-skeleton interface and calcification in reef corals. Proc. Natl. Acad. Sci. U.S.A. 110, 1634-1639. doi: $10.1073 /$ pnas. 1216153110

Vermeij, M. J. A., Marhaver, K. L., Huijbers, C. M., Nagelkerken, I., and Simpson, S. D. (2010). Coral larvae move toward reef sounds. PLoS ONE 5:e10660. doi: 10.1371/journal.pone.0010660

Veron, J. E. N. (2000). Corals of the World, Edited by M. Stafford-Smith. Townsville, QLD: Australian Institute of Marine Science. p. 1382.

Vidal-Dupiol, J., Dheilly, N. M., Rondon, R., Grunau, C., Cosseau, C., Smith, K. M., et al. (2014). Thermal stress triggers broad Pocillopora damicornis transcriptomic remodeling, while Vibrio coralliilyticus infection induces a 
more targeted immuno-suppression response. PLOS ONE 9:e107672. doi: 10.1371/journal.pone.0107672

Vidal-Dupiol, J., Zoccola, D., Tambutte, E., Grunau, C., Cosseau, C., Smith, K. M., et al. (2013). Genes related to ion-transport and energy production are upregulated in response to $\mathrm{CO}_{2}$-driven $\mathrm{pH}$ decrease in corals: new insights from transcriptome analysis. PLOS ONE 8:e58652. doi: 10.1371/journal.pone. 0058652

Wright, R. M., Aglyamova, G. V., Meyer, E., and Matz, M. V. (2015). Gene expression associated with white syndromes in a reef building coral, Acropora hyacinthus. BMC Genomics 16:371. doi: 10.1186/s12864-0151540-2

Zhang, H., Hou, Y., Miranda, L., Campbell, D. A., Sturm, N. R., Gaasterland, T., et al. (2007). Spliced leader RNA trans-splicing in dinoflagellates. Proc. Natl. Acad. Sci. U.S.A. 104, 4618-4623. doi: 10.1073/pnas.0700258104
Zhao, X. L., Yu, H., Kong, L. F., and Li, Q. (2012). Transcriptomic responses to salinity stress in the pacific oyster crassostrea gigas. PLoS ONE 7:e46244. doi: 10.1371/journal.pone.0046244

Conflict of Interest Statement: The authors declare that the research was conducted in the absence of any commercial or financial relationships that could be construed as a potential conflict of interest.

Copyright (C) 2016 Davies, Marchetti, Ries and Castillo. This is an open-access article distributed under the terms of the Creative Commons Attribution License (CC BY). The use, distribution or reproduction in other forums is permitted, provided the original author(s) or licensor are credited and that the original publication in this journal is cited, in accordance with accepted academic practice. No use, distribution or reproduction is permitted which does not comply with these terms. 